\title{
Comparative metabonomic analysis of hepatotoxicity induced by acetaminophen and its less toxic meta-isomer
}

\author{
Michael Kyriakides $^{1} \cdot$ Lea Maitre $^{1} \cdot$ Brendan D. Stamper $^{2} \cdot$ Isaac Mohar $^{3}$. \\ Terrance J. Kavanagh ${ }^{3} \cdot$ John Foster $^{4} \cdot$ Ian D. Wilson $^{1} \cdot$ Elaine Holmes $^{1}$ • \\ Sidney D. Nelson ${ }^{3} \cdot$ Muireann Coen ${ }^{1}$
}

Received: 18 November 2015 / Accepted: 23 November 2015 / Published online: 9 January 2016

(C) The Author(s) 2016. This article is published with open access at Springerlink.com

\begin{abstract}
The leading cause of drug-induced liver injury in the developed world is overdose with $N$-acetyl-p-aminophenol (APAP). A comparative metabonomic approach was applied to the study of both xenobiotic and endogenous metabolic profiles reflective of in vivo exposure to APAP $(300 \mathrm{mg} / \mathrm{kg}$ ) and its structural isomer $N$-acetyl- $m$-aminophenol (AMAP; $300 \mathrm{mg} / \mathrm{kg}$ ) in C57BL/6J mice, which was anchored with histopathology. Liver and urine samples were collected at $1 \mathrm{~h}, 3 \mathrm{~h}$ and $6 \mathrm{~h}$ post-treatment and analyzed by ${ }^{1} \mathrm{H}$ nuclear magnetic resonance (NMR) spectroscopy and gas chromatography-mass spectrometry (liver only). Histopathology revealed the presence of centrilobular necrosis from $3 \mathrm{~h}$ post-APAP treatment, while an AMAP-mediated necrotic endpoint was not observed within the timescale of this study, yet two of five treated mice showed minimal centrilobular eosinophilia. The ${ }^{1} \mathrm{H}-\mathrm{NMR}$ xenobiotic metabolic profile of APAP-treated animals comprised of mercapturate (urine and liver) and glutathionyl (liver) conjugates detected
\end{abstract}

Electronic supplementary material The online version of this article (doi:10.1007/s00204-015-1655-x) contains supplementary material, which is available to authorized users.

Muireann Coen

m.coen@imperial.ac.uk

1 Biomolecular Medicine, Division of Computational and Systems Medicine, Department of Surgery and Cancer, Imperial College London, London SW7 2AZ, UK

2 School of Pharmacy, Pacific University, Hillsboro, OR 97123, USA

3 Departments of Medicinal Chemistry and Environmental and Occupational Health Sciences, University of Washington, Seattle, WA 98195, USA

4 ToxPath Sciences Ltd, 1 Troutbeck Avenue, Congleton, Cheshire CW12 4JA, UK at $1 \mathrm{~h}$ post-treatment. This finding corroborated the hepatic endogenous metabolic profile which showed depletion of glutathione from $1 \mathrm{~h}$ onwards. In contrast, AMAP glutathionyl conjugates were not detected, nor was AMAP-induced depletion of hepatic glutathione observed. APAP administration induced significant endogenous hepatic metabolic perturbations, primarily linked to oxidative and energetic stress, and perturbation of amino acid metabolism. Early depletion of glutathione was followed by depletion of additional sulfur-containing metabolites, while altered levels of mitochondrial and glycolytic metabolites indicated a disruption of energy homeostasis. In contrast, AMAP administration caused minimal, transient, distinct metabolic perturbations and by $6 \mathrm{~h}$ the metabolic profiles of AMAP-treated mice were indistinguishable from those of controls.

Keywords $N$-acetyl- $p$-aminophenol (APAP) $\cdot N$-acetyl$m$-aminophenol (AMAP) $\cdot$ Metabonomics/Metabolic Phenotyping · Nuclear magnetic resonance spectroscopy · Hepatotoxicity

\section{Introduction}

Paracetamol otherwise known as acetaminophen or $N$-acetyl-p-aminophenol (APAP) is a commonly used analgesic and antipyretic drug that can cause extensive liver damage after an excessive dose and is the leading cause of drug-induced liver injury in the USA (Lee 2012). Consequently, it has been extensively studied and is classified as a 'model hepatotoxin' given the extensive knowledge of its mechanism of hepatotoxicity (McGill et al. 2012a; Russmann et al. 2009).

APAP predominantly undergoes conjugation via glucuronidation or sulphation in the liver $(>90 \%$ of a therapeutic 
dose). Cytochrome P450 enzymes, principally CYP2E1 (rodents and humans) and CYP3A4 (humans), are responsible for oxidation of APAP to its reactive metabolite, $N$-acetyl- $p$-benzoquinone imine (NAPQI) (Dahlin and Nelson 1982; Miner and Kissinger 1979). NAPQI is a potent oxidant and electrophile, which leads to glutathione depletion, as this represents the primary conjugation and detoxification mechanism, but also protein thiol oxidation, crosslinking and arylation (Bessems and Vermeulen 2001; Miner and Kissinger 1979).

NAPQI has also been shown to covalently bind to mitochondrial proteins (Halmes et al. 1996; Landin et al. 1996), and this is considered to be an important hallmark of APAP-induced hepatotoxicity (Jaeschke et al. 2012). Physiologically, the mitochondria display an altered morphology, including an abrupt increase in volume as a result of mitochondrial membrane transition pore opening (Masubuchi et al. 2005; Pierce et al. 2002). Functionally, there is an overall disruption as reflected by mitochondrial oxidative stress, ATP pool depletion and lower respiration rates (Katyare and Satav 1989; Placke et al. 1987), together with DNA fragmentation mediated by the translocation of nucleases located in the mitochondrial inter-membrane space (Bajt et al. 2006).

$N$-acetyl- $m$-aminophenol (AMAP), a reportedly nonhepatotoxic regioisomer of APAP in mice and hamsters (Nelson 1980; Roberts and Jollow 1978), has been used in comparative studies with APAP (Beyer et al. 2007; Hadi et al. 2013; Howell et al. 2014; Stamper et al. 2010). The comparison of regioisomers with differential toxic liabilities presents significant potential for elucidating mechanisms of toxicity. AMAP is thought to be less hepatotoxic than APAP because it binds to mitochondrial proteins to a lesser extent and primarily binds to cytosolic and microsomal proteins (Streeter et al. 1984; Tirmenstein and Nelson 1989). However, recent evidence suggests that AMAP is toxic in precision-cut liver slices from rats and humans (Hadi et al. 2013), and primary human hepatocytes (Xie et al. 2015), and therefore, further work is required to understand the differential toxicology of the regioisomers across and within species.

Metabonomics is a 'top-down' system approach used to describe the metabolic phenotype of biological samples under specific biological conditions or in response to an intervention (Nicholson et al. 1999). Metabonomics (and the related field of metabolomics) has found widespread application in the investigation of molecular toxicology, where the site- and mechanism-specific effects of a toxin or therapeutic intervention can be investigated (Coen 2014; Coen et al. 2008; Lindon et al. 2005). Earlier metabonomic studies have been applied to investigate the metabolism of APAP in both in vivo models and humans (Bales et al. 1984; Nicholls et al. 1995; Spurway et al. 1990). More recently, studies of APAP in mice reported a significant perturbation of metabolites involved in the biosynthesis of glutathione; opthalmate, 5-oxoproline and taurine (Soga et al. 2006; Ghauri et al. 1993), as well as numerous system-level metabolic changes that together suggested a disturbance of energy metabolism, more specifically of increased rates of glycolysis and impaired $\beta$-oxidation (Coen et al. 2003, 2004). Further evidence for APAP-induced inhibition of fatty acid $\beta$-oxidation includes the observation of elevated levels of serum long-chain acyl-carnitines in mice (Chen et al. 2009) and children (Bhattacharyya et al. 2014).

Here we describe the results of a multiplatform metabonomic study, using gas chromatography-mass spectrometry (GC-MS) and ${ }^{1} \mathrm{H}$ nuclear magnetic resonance (NMR) spectroscopy to characterize the system-level xenobiotic metabolic profile together with the hepatic endogenous metabolic consequences of APAP and AMAP administration in mice, with a particular focus on the identification of differential discriminatory metabolites reflective of mitochondrial function and oxidative stress.

\section{Materials and methods}

\section{Animal handing and treatment}

Male C57BL/6J mice ( $n=50$, aged 10 weeks) purchased from Jackson Laboratory (Bar Harbor, ME, USA) were kept in a pathogen-free environment at the University of Washington. The animals were housed in Association for Assessment and Accreditation of Laboratory Animal Care International (AAALAC)-accredited temperature-controlled rooms with a 12-h light/dark cycle throughout the study. They were acclimated to the facility for 1 week during which they had access to ad libitum rodent chow diet and acidified sterile water $(\mathrm{pH}=2.77)$. All experiments were conducted under protocol approved by the Institutional Animal Care and Use Committee of the University of Washington.

After a fasting period of $12 \mathrm{~h}$, the mice were treated with APAP $(300 \mathrm{mg} / \mathrm{kg}$ in saline; $n=15)$, AMAP $(300 \mathrm{mg} / \mathrm{kg}$ in saline; $n=15$ ) or sterile saline (control; $n=20$ ), via I.P. injections of $15 \mu \mathrm{l} / \mathrm{g}$ body weight. The selected APAP dose has been previously reported to cause marked liver damage in mice (Masubuchi et al. 2005; McGill et al. 2012b) and an equimolar dose of AMAP was selected for comparative purposes which has previously been reported to be nontoxic in this strain of mice (Fountoulakis et al. 2000; Priyadarsiny et al. 2008). Food was returned to mice after APAP/ AMAP administration.

Mice from each treatment group were euthanized via $\mathrm{CO}_{2}$ inhalation and cervical dislocation at $1 \mathrm{~h}, 3 \mathrm{~h}$ and $6 \mathrm{~h}$ post-treatment $(1 \mathrm{~h}, 3 \mathrm{~h}$ and $6 \mathrm{~h}$, respectively; $n=5$ for 
drug treatment groups at each time-point and $n=6, n=7$ and $n=7$ for the control groups at $1 \mathrm{~h}, 3 \mathrm{~h}$ and $6 \mathrm{~h}$, respectively). At each time-point, blood from a cardiac puncture was collected into serum separator tubes (Microtainer, BD Biosciences, San Jose, California, USA) together with liver sections from the left lateral lobe, which were immediately snap-frozen in liquid nitrogen and stored at $-80{ }^{\circ} \mathrm{C}$. Sera fractions were collected following incubation of the collected blood at room temperature $(30 \mathrm{~min})$ and centrifugation $(4000 \times g$ for $6 \mathrm{~min})$. Urine was collected on ice in conical tubes containing sodium azide $(1 \mathrm{~mL}, 1 \% \mathrm{w} / \mathrm{v}$ water) across the following time periods: $0-1,1-3$ and 3-6 h ( $n=3$ for APAP- and AMAP-treated groups at $1 \mathrm{~h}$ and $n=5$ for all other groups).

\section{Liver histopathology}

Liver tissue sections from the medial lobe were fixed in $10 \%$ paraformaldehyde (formalin) overnight prior to dehydration, paraffin embedding and staining with hematoxylin and eosin (H\&E). These were examined using light microscopy, and the extent of centrilobular necrosis was assessed without any prior knowledge of the treatment class. The histopathological findings were carried out for all treated animals and one control per time-point and were graded as recommended in current guidelines for reporting these changes (Ward and Thoolen 2011). The scoring criteria for centrilobular necrosis were as follows: 0 (no lesion), 1 (necrosis of single layer of cells around the central vein affecting $<20 \%$ of the central veins in the liver lobes; minimal), 2 (necrosis of single layer of hepatocytes around all of the central veins in the liver lobes; mild) and 3 (necrosis of 2-4 layers of hepatocytes around all of the central veins in most liver lobes; moderate). The histopathological analysis also included assessment and grading of periportal glycogen, focal mixed inflammatory reaction, centrilobular eosinophilia and panlobular fat vacuolation with the analysis for individual animals provided in the Suppl. material (Table 1) together with the grading explanations.

\section{${ }^{1}$ H-NMR spectroscopy of the hepatic aqueous soluble component}

Liver tissue metabolite extraction for ${ }^{1} \mathrm{H}-\mathrm{NMR}$ spectroscopic analysis was performed according to the protocol described by Beckonert et al. (2007). Briefly, ice-cold acetonitrile/water $(1.5 \mathrm{~mL}, 1: 1)$ was added to the liver tissue samples (average weight of $41.4 \mathrm{mg}$ and STD $\pm 3.1 \mathrm{mg}$. The samples were homogenized with $5 \mathrm{~mm}$ stainless steel beads in a homogenizer (Qiagen Tissue Lyser, Retsch $\mathrm{GmBH}$, Haan, Germany) at $25 \mathrm{~Hz}$ for $8 \mathrm{~min}$. The samples were then kept on ice for $10 \mathrm{~min}$ prior to centrifugation at $17,000 \times g$ for $15 \mathrm{~min}$ at $4{ }^{\circ} \mathrm{C}$ (Biofuge Pico, Heraeus, Hanau, Germany). The supernatant was concentrated and dried overnight in a centrifugal evaporator (SpeedVac, Thermoscientific, Waltham, Massachusetts, USA) at $30{ }^{\circ} \mathrm{C}$. The resultant dried supernatant was reconstituted in phosphate buffer $(600 \mu \mathrm{L}$ of a $0.2 \mathrm{M}$ solution containing $99.9 \% \mathrm{D}_{2} \mathrm{O}, 3 \mathrm{mM}$ sodium azide $\left(\mathrm{NaN}_{3}\right)$ and $1 \mathrm{mM}$ 3-(trimethylsilyl)-[2,2,3,3- $\left.{ }^{2} \mathrm{H}_{4}\right]$-propionic acid sodium salt (TSP)), vortexed for $30 \mathrm{~s}$ and then centrifuged at 17,000x for $15 \mathrm{~min}$ at $4{ }^{\circ} \mathrm{C}$ (Biofuge Pico). The supernatant (550 $\mu \mathrm{L}$ ) was placed in $5 \mathrm{~mm}$ NMR tubes (outer diameter; NMR Precision tube 507-HP-7, Norell, Landisville, New Jersey, USA). NMR spectral data were acquired on a Bruker Avance-600 spectrometer operating at $600.13 \mathrm{MHz}$ $(14.1 \mathrm{~T}){ }^{1} \mathrm{H}$ frequency and at a temperature of $300 \mathrm{~K}$ using a Bruker TXI probe (Bruker Biospin, Rheinstetten, Germany) and an automated sample handling carousel (Bruker). A standard one-dimensional solvent suppression pulse sequence was used to acquire the free induction decay (FID; relaxation delay $-90^{\circ}$ pulse $-4 \mu$ s delay $-90^{\circ}$ pulse-mixing time-90 ${ }^{\circ}$ pulse-acquire FID) (Beckonert et al. 2007). The $\mathrm{D}_{2} \mathrm{O}$ present in the buffer provided a field frequency lock, whilst the TSP served as the chemical shift reference compound $\left(\delta^{1} \mathrm{H}=0.00\right)$. For each experiment, 256 transients were collected into 64,000 data points using a spectral width of $12,000 \mathrm{~Hz}$, with a relaxation delay of $4 \mathrm{~s}$, mixing time of $100 \mathrm{~ms}$ and an acquisition time of $4.5 \mathrm{~s}$.

\section{${ }^{1}$ H-NMR spectroscopy of urine}

Urine samples were prepared for ${ }^{1} \mathrm{H}-\mathrm{NMR}$ spectroscopy as previously described (Beckonert et al. 2007). Briefly, urine was mixed with phosphate buffer $(2: 1,600 \mu \mathrm{L}$ total volume; same buffer with the hepatic aqueous extract analysis) and vortexed for $1 \mathrm{~min}$. The samples were then centrifuged at $17,000 \times g$ for $15 \mathrm{~min}$ at $4{ }^{\circ} \mathrm{C}$ (Biofuge Pico) and the supernatants $(550 \mu \mathrm{L})$ transferred to $5 \mathrm{~mm}$ NMR tubes (507-HP-7). ${ }^{1} \mathrm{H}-\mathrm{NMR}$ spectral data were acquired on a Bruker Avance-600 spectrometer as described for the aqueous hepatic extracts.

\section{${ }^{1}$ H-NMR spectral data processing}

The ${ }^{1} \mathrm{H}-\mathrm{NMR}$ spectra were initially processed in TopSpin 3.0 NMR Software (Bruker), where a line-broadening factor of $0.3 \mathrm{~Hz}$ was applied to all spectra prior to Fourier transformation (FT). The spectra were then manually phased, baseline-corrected and referenced to the TSP peak for the aqueous soluble liver extract and urine spectra or lactate peak for the sera spectra. Full-resolution ${ }^{1} \mathrm{H}-\mathrm{NMR}$ 
data were imported into MATLAB (R2012, Mathworks Inc., Natick, Massachusetts, USA), using an in-house script, for further processing, which included the removal of the TSP and water resonance regions before performing probabilistic quotient normalization (Dieterle et al. 2006). This is a robust method of normalization which corrects for the differential dilution of urine samples, a factor which affects the concentration of all metabolites or intensity of all resonances in a spectrum. This dilution factor correction thus enables the detection of the biologically relevant, relative concentration changes in selected metabolites. The method scales the spectra based on the most probable dilution factor, calculated from the distribution of quotients of the intensity of each spectral data point relative to a reference spectrum. This method has shown to be more robust for normalization of metabolic profiling data sets than total area integral normalization (Dieterle et al. 2006). Spectral metabolite assignments were achieved using Statistical TOtal Correlation Spectroscopy (STOCSY) (Cloarec et al. 2005), 2D-NMR experiments (Correlation Spectroscopy), spectral databases (Human Metabolome Database and Biological Magnetic Resonance Bank), software including Chenomx NMR Suite (Chenomx, Edmonton, Alberta, Canada) and previously published assignments (Nicholson et al. 1995). Furthermore, the following hepatic metabolites were identified by 'spike-in' experiments with the pure standard compounds: adenosine monophosphate (AMP), succinate, 2-aminoadipate, dimethylamine, phosphocholine, choline and glutathione (reduced and oxidized). A summary of the integral regions of the endogenous metabolites and the drug-related resonances is displayed in Table 2 and Table 3 in the Suppl. material, respectively. Finally, the assignment of APAP and AMAP metabolites was based on existing literature (Bales et al. 1984; Nicholls et al. 2006).

In-house scripts were used to calculate the integral of resonances belonging to drug related, and parent compounds in both treatment groups at $1 \mathrm{~h}(n=3$ for each group), in order to estimate their relative abundance to the parent molecule. The integrated resonances in the hepatic extract ${ }^{1} \mathrm{H}-\mathrm{NMR}$ profiles were as follows: APAP parent $\left(\delta^{1} \mathrm{H}=7.26\right.$; doublet $)$, APAP glucuronide conjugate $\left(\delta^{1} \mathrm{H}=7.15\right.$; doublet), APAP glutathionyl conjugate $\left(\delta^{1} \mathrm{H}=6.96\right.$; doublet $)$, APAP- $N$-acetylcysteinyl conjugate $\left(\delta^{1} \mathrm{H}=1.85\right.$; singlet), AMAP glucuronide conjugate $\left(\delta^{1} \mathrm{H}=7.24\right.$; singlet $)$ and AMAP parent $\left(\delta^{1} \mathrm{H}=7.03\right.$; singlet). The resonances used in the urine ${ }^{1} \mathrm{H}-\mathrm{NMR}$ metabolic profiles were as follows: APAP parent $\left(\delta^{1} \mathrm{H}=6.88\right.$; doublet), APAP glucuronide conjugate $\left(\delta^{1} \mathrm{H}=7.36\right.$; doublet), APAP sulfate conjugate $\left(\delta^{1} \mathrm{H}=7.31\right.$; doublet $)$, APAP cysteinyl conjugate $\left(\delta^{1} \mathrm{H}=7.50\right.$; singlet $)$, APAP- $N$-acetylcysteinyl conjugate ( $\delta^{1} \mathrm{H}=1.86$; singlet), AMAP glucuronide conjugate $\left(\delta^{1} \mathrm{H}=7.24\right.$; singlet), AMAP sulfate conjugate $\left(\delta^{1} \mathrm{H}=7.43\right.$; triplet $)$, AMAP parent $\left(\delta^{1} \mathrm{H}=7.02\right.$; singlet) and APAP methoxy conjugate $\left(\delta^{1} \mathrm{H}=3.88\right.$; singlet). Each integral was adjusted for the equivalent number of protons before the ratio to the parent molecule was calculated. Finally, the integral of the resonances belonging to endogenous metabolites were also calculated, including total glutathione (oxidized and reduced; $\delta^{1} \mathrm{H}=2.55$; multiplet), succinate ( $\delta^{1} \mathrm{H}=2.41$; singlet), 2-aminoadipate $\left(\delta^{1} \mathrm{H}=2.25\right.$; triplet $)$, glutamate $\left(\delta^{1} \mathrm{H}=2.35\right.$; multiplet $)$, D-3-Hydroxybutyrate (D-3-HB; $\delta^{1} \mathrm{H}=1.20$; doublet), glucose $\left(\delta^{1} \mathrm{H}=5.25\right.$; doublet $), \operatorname{AMP}\left(\delta^{1} \mathrm{H}=8.61\right.$; singlet $)$ and valine $\left(\delta^{1} \mathrm{H}=1.04\right.$; doublet $)$.

\section{GC-MS analysis of the hepatic aqueous soluble component}

Liver tissue samples of an average weight of $25.25 \mathrm{mg}$ and STD of $\pm 0.22 \mathrm{mg}$ were added to an ice-cold HPLCgrade water/methanol mixture $(1: 1,1.2 \mathrm{~mL}$ total volume) and homogenized with zirconia beads at $6500 \mathrm{~Hz}$ (Precellys, Montigny-le-Bretonneux, France) for two 45-s periods with an intermediate 5-min cooling period on dry ice. The homogenized mixtures were incubated for $45 \mathrm{~min}$ on ice before centrifugation at $17,000 \times g$ for $15 \mathrm{~min}$ at $4{ }^{\circ} \mathrm{C}$ (Biofuge Pico). The resulting supernatant was mixed with ice-cold methanol/water $(2: 1,0.5 \mathrm{~mL})$ to facilitate protein precipitation. The samples were then incubated overnight at $-4{ }^{\circ} \mathrm{C}$ and centrifuged the following day at $17,000 \times g$ for 15 min at $4{ }^{\circ} \mathrm{C}$ (Biofuge Pico).

Quality control (QC) samples were prepared by collecting and pooling $5 \mu \mathrm{L}$ aliquots from each sample prior to drying overnight in a centrifugal concentrator (SpeedVac). The resulting dried supernatants were then derivatized using the methoximation/silylation protocol provided by Fiehn (2008). Briefly, myristic- $\mathrm{d}_{27}$ acid (5 $\mu \mathrm{L}$ of a $6-\mathrm{mM}$ solution in anhydrous pyridine) and $\mathrm{U}_{-}{ }^{13} \mathrm{C}-\mathrm{D}-\mathrm{Glucose}(20 \mu \mathrm{L}$ of a 1 -mM solution in anhydrous pyridine) were added as standards to each sample for retention time locking and quantification purposes, respectively. For the methoximation step, methoxyamine hydrochloride $(40 \mu \mathrm{L}$ of $0.3 \mathrm{M}$ solution in anhydrous pyridine) was added to each sample and the samples were then incubated at $30{ }^{\circ} \mathrm{C}$ for 90 min with shaking at 30-min intervals. For the silylation step, the samples were incubated with $N$-methyl- $N$-(trimethylsilyl)-trifluoroacetamide ( $90 \mu \mathrm{L}$; MSTFA) at $37^{\circ} \mathrm{C}$ for $30 \mathrm{~min}$. Finally, 2-fluorobiphenyl (10 $\mu \mathrm{L}$ of a $1-\mathrm{mM}$ solution in anhydrous pyridine) was added as an injection standard.

GC-MS analysis was performed on an Agilent 7890 gas chromatograph coupled to a 5975 mass selective detector (MSD) quadruple mass spectrometer (MSD; Agilent Technologies, Santa Clara, California, USA) in accordance with the Fiehn protocol (Fiehn 2008). QC samples were used at the beginning of the run to condition the chromatographic column and thereafter at five sample intervals (Sangster et al. 
2006). The acquired spectra were initially processed with the Automated Mass Spectral Deconvolution and Identification System software (AMDIS, NIST, Gaithersburg, Maryland, USA) by using the Fiehnlib library (Kind et al. 2009). The spectra were then transferred to MATLAB (Mathworks), and an in-house developed MATLAB script was then used to manually inspect the chromatographic peaks of the identified metabolites and remove all of the features that were not consistently present in the QC samples, before integration of the remaining features (Behrends et al. 2011).

Overall, the analysis led to the analysis of 38 molecular species which were subsequently tested for statistically significant differences between treatment groups. Reasons for metabolite exclusion prior to analysis included poor chromatographic peak shape, peak overlap and an inconsistent presence in the spectra of QC samples. The 38 selected metabolites were normalized through the fitting of QCderived polynomial curves for each metabolic feature (Dunn et al. 2011) followed by log median factor normalization to account for inter-batch effects. The overall normalization process was evaluated by principal component analysis (PCA) to explore the effect of each normalization step on the inherent clustering (biochemical similarity) of samples.

\section{Statistical analysis}

Prism 5.0 (Graphpad; La Jolla, CA, USA) was used for nonparametric univariate analysis of the ${ }^{1} \mathrm{H}-\mathrm{NMR}$ spectroscopic analysis (Kruskal-Wallis with Dunn's multiple test correction) and for parametric analysis of the log-transformed GC-MS data (analysis of variance (ANOVA) with a Bonferroni multiple correction test). A significance threshold value of $p<0.05$ was set throughout. Please note that inter-time-point statistical comparisons were avoided due to the fluctuating metabolite levels in the control cohorts over time, such as those of glucose and AMP. Furthermore, six liver samples ( $n=3$ for control at $1 \mathrm{~h}, n=1$ for APAP at $3 \mathrm{~h}, n=1$ for control at $6 \mathrm{~h}$ and $n=1$ for AMAP at $6 \mathrm{~h}$ ) were excluded from the ${ }^{1} \mathrm{H}-\mathrm{NMR}$ spectroscopic analysis as they were identified as outliers following a preliminary

\section{B}

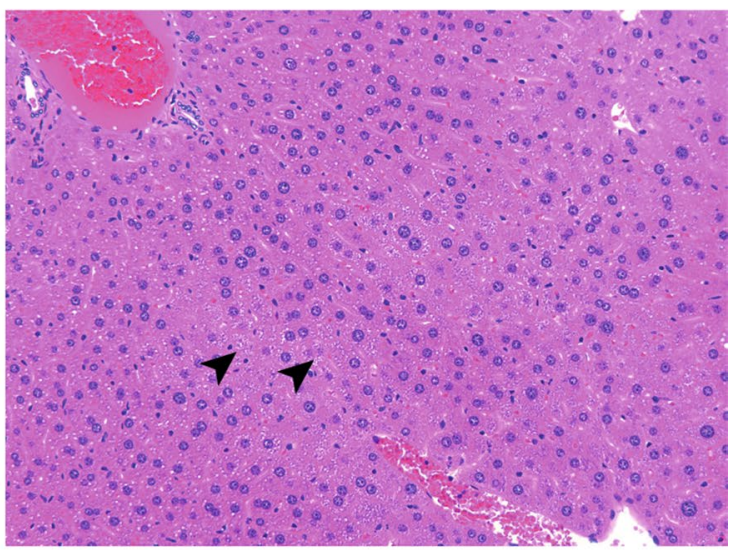

D

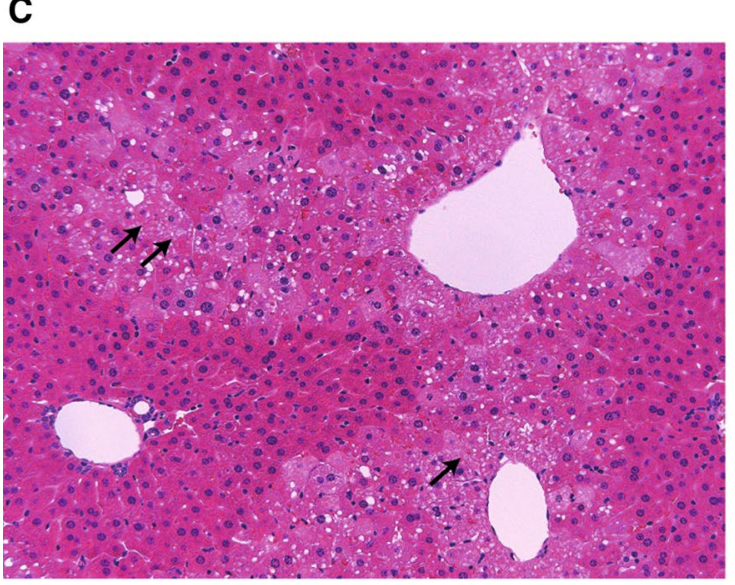

Fig. 1 Representative histopathology slides of the APAP-, AMAPtreated and control groups at $6 \mathrm{~h}$. No visible damage is present in the control group (a), panlobular fat vacuolation is visible in the AMAP-

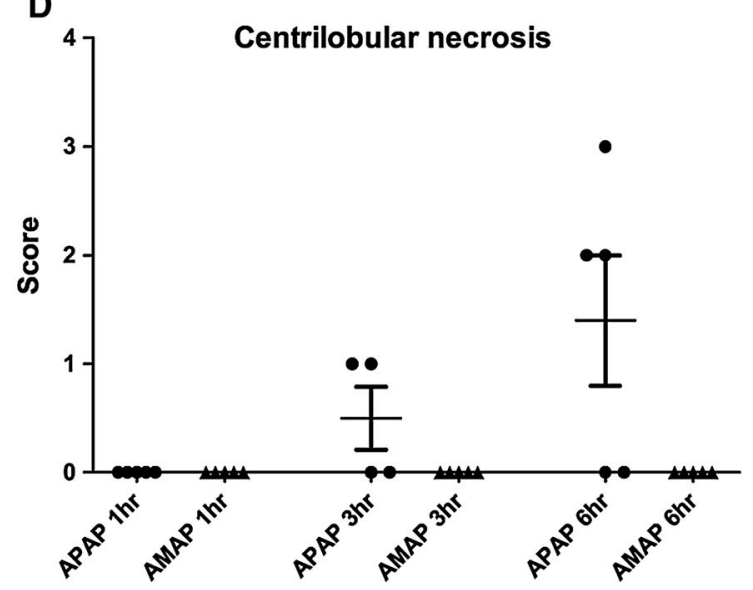

treated group (b; arrowhead) and centrilobular necrosis is present in the APAP-treated group (c; arrows). A summary of the centrilobular necrosis scores of the AMAP- and APAP-treated groups is presented in $\mathbf{d}$ 

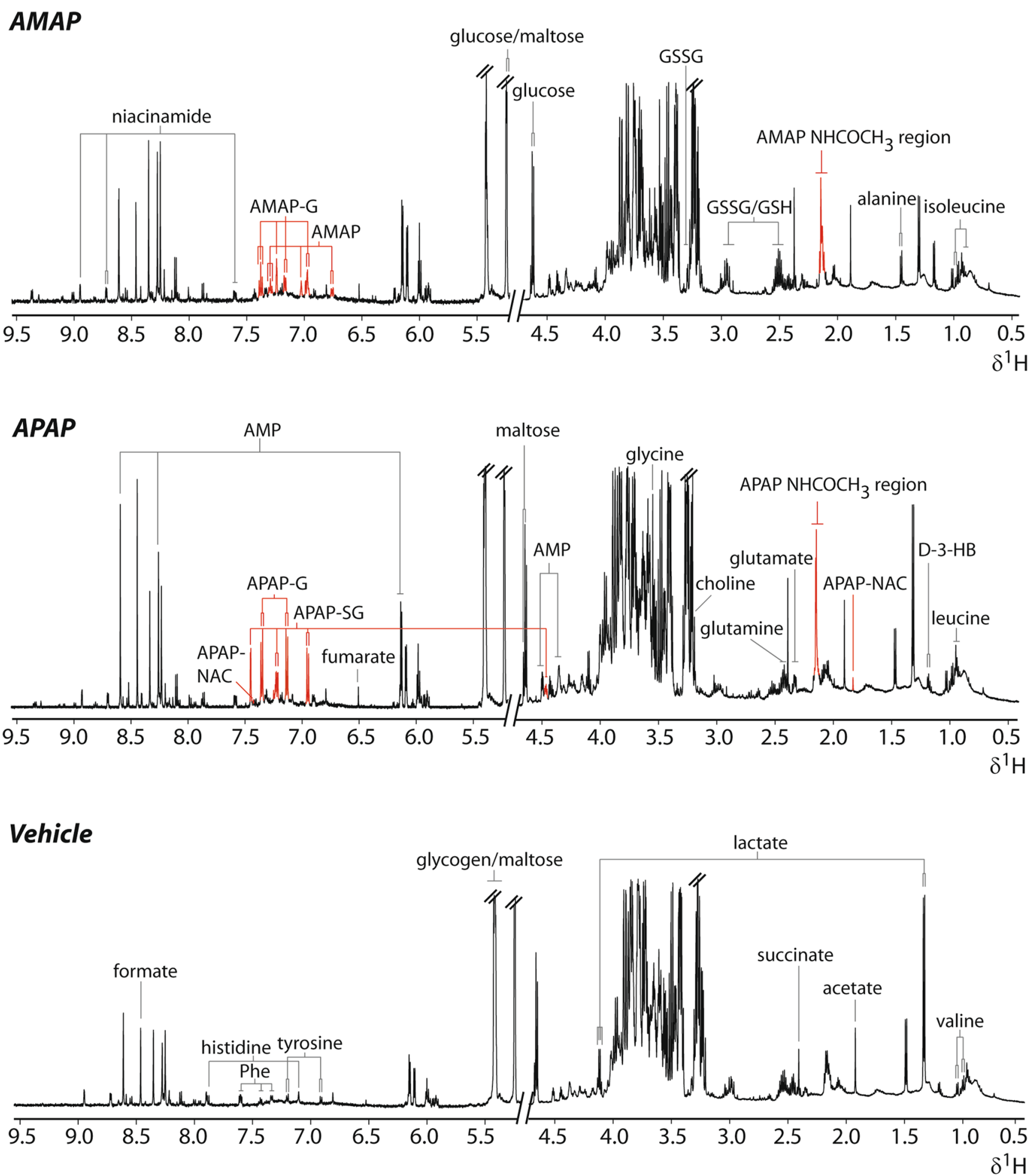

Fig. 2 Representative ${ }^{1} \mathrm{H}-\mathrm{NMR}$ spectra of hepatic extract metabolic profiles of the APAP, AMAP and control groups at $1 \mathrm{~h}$. Resonances assigned to drug-related molecules have been colored in red. Key: APAP/AMAP-G, APAP/AMAP glucuronide; APAP-SG, APAP glutathionyl; APAP-NAC, APAP- $N$-acetylcysteinyl; APAP/AMAP-
$\mathrm{NHCOCH}_{3}$, APAP/AMAP $N$-acetyl resonance; GSH, reduced glutathione; GSSG, oxidized glutathione; Phe, phenylalanine; D-3-HB, D-3-hydroxybutyrate; AMP, adenosine monophosphate, overlapped resonances from glucose/glycogen/maltose labelled 
A
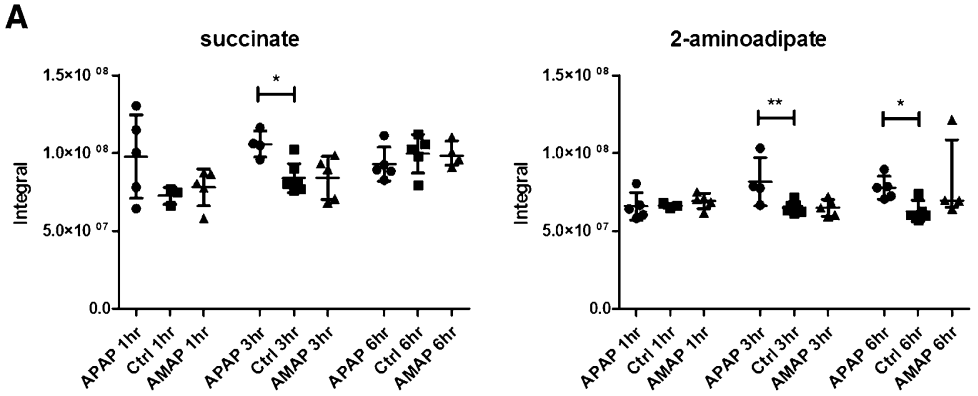

valine

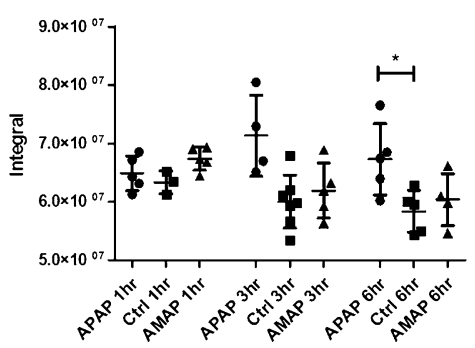

glutamate

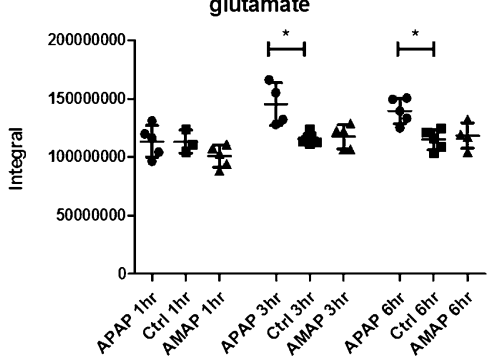

B

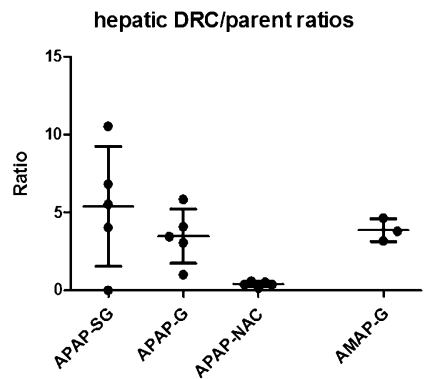

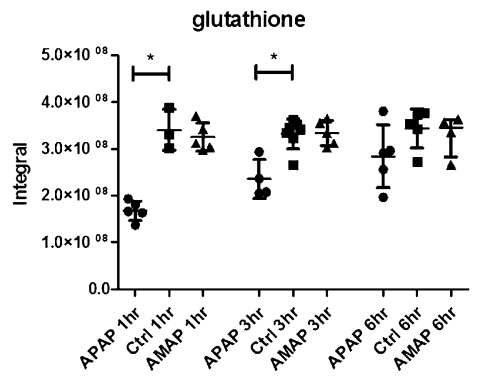

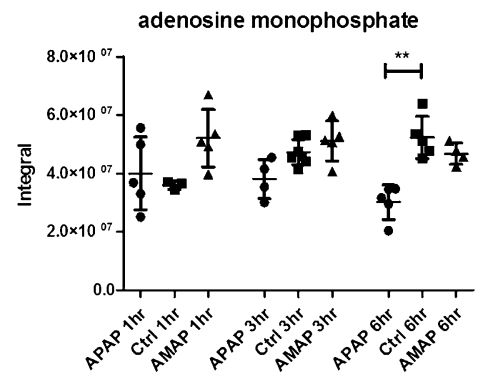

glucose

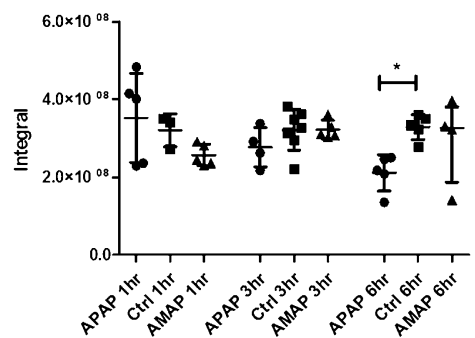

urinary DRC/parent ratios

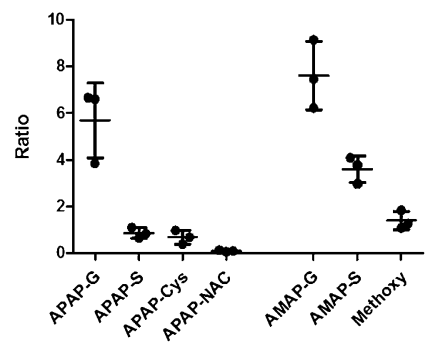

Fig. 3 Integrals of discriminatory metabolites identified by the ${ }^{1} \mathrm{H}-$ NMR spectroscopic analysis of hepatic extracts after APAP/AMAP administration (A). Drug metabolite ratios of APAP and AMAP conjugates to their respective parent molecules in the hepatic extract and urinary metabolic profiles at the 1-h time-point are also shown (B). Kruskal-Wallis test coupled to Dunn's multiple test correction was

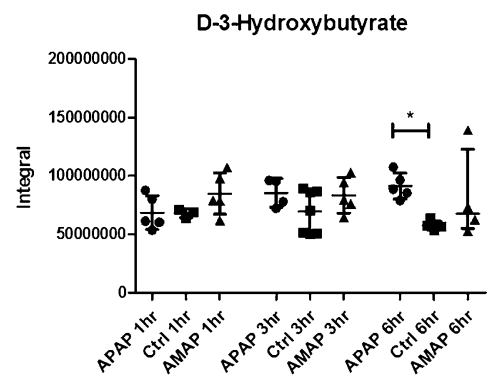

used to calculate the statistical significance of endogenous metabolic perturbations, which is indicated by the asterisks, * and ** $(p<0.05$ and $p<0.01$, respectively). Key -SG, glutathionyl conjugate; $-\mathrm{S}$, sulfate conjugate; -G, glucuronide conjugate; -Cys, cysteinyl conjugate; -NAC, $N$-acetylcysteinyl conjugate 
Table 1 Summary of discriminatory metabolites identified by ${ }^{1} \mathrm{H}-\mathrm{NMR}$ spectroscopic analysis of hepatic extracts after APAP/AMAP administration

\begin{tabular}{|c|c|c|c|}
\hline \multirow{2}{*}{$\begin{array}{l}\text { Treatment } \\
\text { group }\end{array}$} & \multicolumn{3}{|c|}{ Time-points } \\
\hline & $1 \mathrm{~h}$ & $3 \mathrm{~h}$ & $6 \mathrm{~h}$ \\
\hline APAP & $\downarrow$ Glutathione* & 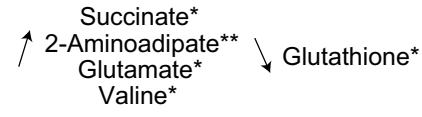 & 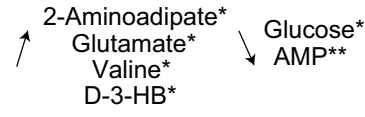 \\
\hline AMAP & $\begin{array}{l}\text { No significant } \\
\text { changes }\end{array}$ & $\begin{array}{l}\text { No significant } \\
\text { changes }\end{array}$ & $\begin{array}{l}\text { No significant } \\
\text { changes }\end{array}$ \\
\hline
\end{tabular}

Kruskal-Wallis test coupled to Dunn's multiple test correction was used to calculate the statistical significance, which is indicated by the asterisks, $*$ and $* *$ ( $p<0.05$ and $p<0.01$, respectively). Key: D-3-HB-D-3-hydroxybutyrate

principal component analysis due to poor spectral quality. Finally, the urine metabolic profiles were not analyzed statistically due to insufficient numbers per treatment group per time-point, as a result of insufficient volume collected from the animals within the short time-collection windows.

\section{Results}

\section{Liver histopathology}

Mice given APAP showed histopathological changes at all time-points examined. At $1 \mathrm{~h}$, one of the treated mice showed a grade 1 centrilobular eosinophilia, while a second animal showed a grade 2 panlobular fat vacuolation (Suppl. Table 1). Two of the APAP-treated animals showed grade 1 focal inflammatory cell infiltration at $1 \mathrm{~h}$ post-treatment.

At $3 \mathrm{~h}$, all examined animals showed centrilobular eosinophilia of grades 3-4 and two of these animals with grade 4 centrilobular eosinophilia showed a grade 1 centrilobular necrosis.

At $6 \mathrm{~h}$, four of the five livers examined showed centrilobular eosinophilia of grades 3-4 and three of the five livers examined showed centrilobular necrosis of grades 2-3 (Suppl. Table 1). Figure 1 provides a representative slide of a control (1A), AMAP (1B)- and APAP (1C)-treated animal at $6 \mathrm{~h}$ post-treatment showing the presence of the centrilobular necrotic lesion (grade 3) following APAP treatment. A summary of the centrilobular necrosis scores at all time-points in the AMAP- and APAP-treated mice is presented in Fig. 1d.

Mice given AMAP did not show any histological changes at time-point $1 \mathrm{~h}$, but at both time-points $3 \mathrm{~h}$ and $6 \mathrm{~h}$ the livers of two of five treated mice showed a grade 1 and grade 2 centrilobular eosinophilia while at timepoint $6 \mathrm{~h}$ one of the mice with centrilobular eosinophilia also showed a grade 2 panlobular fat vacuolation (Suppl. Table 1). Two of the AMAP-treated animals showed a grade 1 focal inflammatory cell infiltration at all timepoints, whereas an additional animal showed a grade 1 focal inflammatory cell infiltration at $1 \mathrm{~h}$ and $6 \mathrm{~h}$ posttreatment (Suppl. Table 1).

\section{APAP and AMAP metabolism in C57BL/6J mice}

The metabolism of APAP and AMAP was characterized in hepatic extracts and urine from the $1 \mathrm{D}{ }^{1} \mathrm{H}-\mathrm{NMR}$ spectroscopic profiles. In the hepatic extracts, APAP and its glucuronide, glutathionyl and $\mathrm{N}$-acetylcysteinyl conjugates were observed at $1 \mathrm{~h}$ (Figs. 2, 3b). In the case of AMAP-treated hepatic extract profiles, the unchanged parent and AMAP glucuronide were the only compounds detected at the equivalent time-point (Figs. 2, 3b). The urinary ${ }^{1} \mathrm{H}$-NMR spectroscopic metabolic profiles revealed the presence of the APAP parent and the APAP glucuronide, sulfate, $N$-acetylcysteinyl and cysteinyl conjugates at $1 \mathrm{~h}$ (Suppl. Fig. 1 and Fig. 3b). In the AMAP-treated mice, the unchanged parent and the glucuronide and sulfate conjugates were detected, but there was no evidence for the excretion of glutathionyl-conjugated compounds (Suppl. Fig. 1 and Fig. 3b). The AMAP glucuronide conjugate was the most abundant metabolite in all sample matrices, while the APAP glutathionyl and glucuronide conjugates were the most abundant compounds detected in liver and urine samples from APAP-dosed mice. These data are presented as metabolite/parent ratios for both liver and urine in Fig. 3b. Lower levels of the xenobiotic metabolites were also detected in the urinary metabolic profiles of the APAP (cysteinyl, glucuronide and sulfate conjugates)- and AMAP-treated mice (glucuronide conjugate) at $3 \mathrm{~h}$.

\section{${ }^{1}$ H-NMR spectroscopic detected endogenous changes in hepatic extracts following AMAP and APAP administration}

Representative ${ }^{1} \mathrm{H}-\mathrm{NMR}$ spectra of hepatic extracts from each treatment group and a control are given in Fig. 2 showing the respective assignment of the key xenobiotic and endogenous 

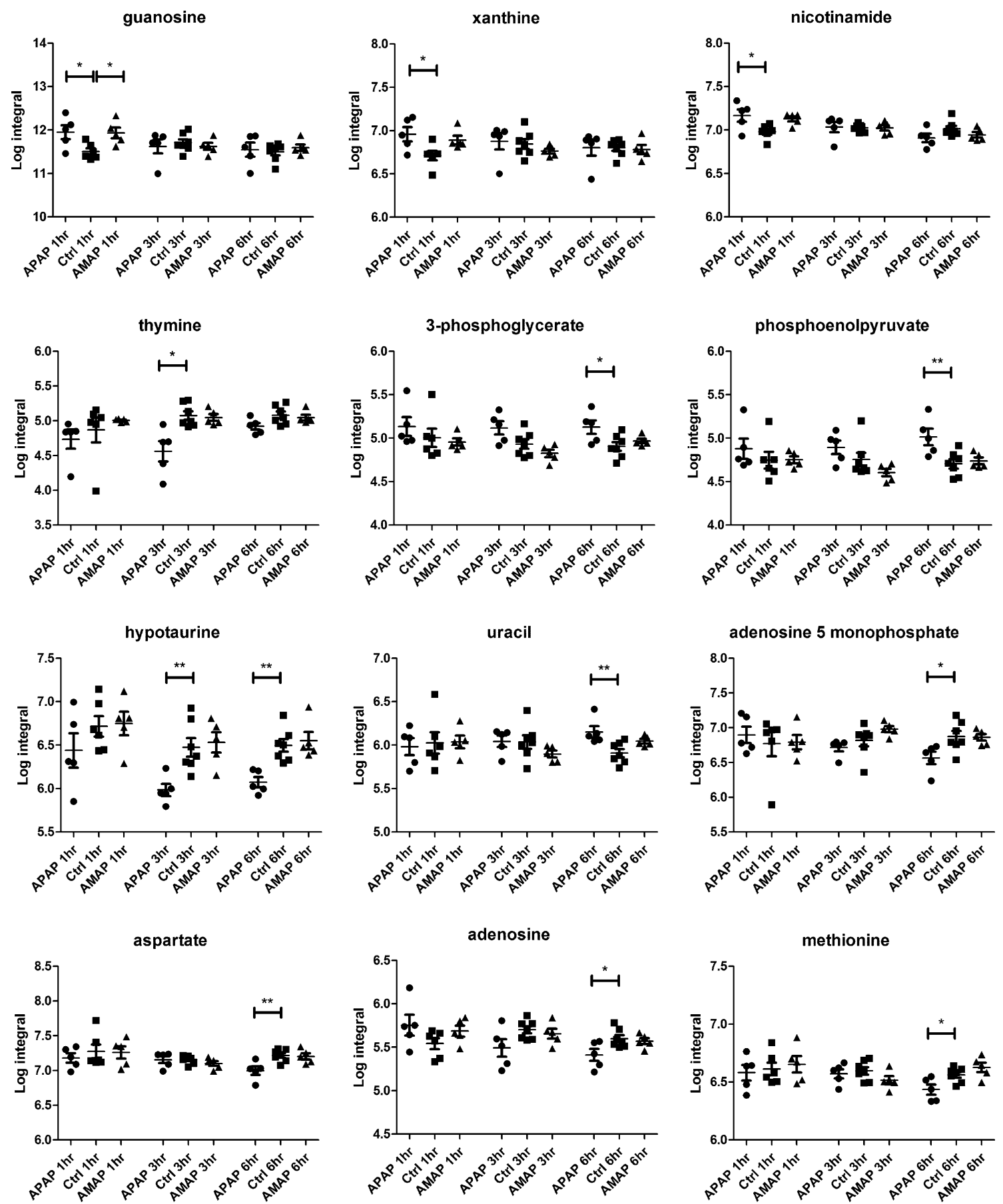

Fig. 4 Integrals of discriminatory metabolites identified by GC-MS analysis of the hepatic extracts after APAP/AMAP administration. ANOVA coupled to Bonferroni multiple test correction was used.

metabolites. Univariate analysis revealed that APAP administration led to the depletion of glutathione (reflecting both oxidized and reduced forms) at $1 \mathrm{~h}$ and $3 \mathrm{~h}$, while succinate, valine, 2-aminoadipate and glutamate were elevated at $3 \mathrm{~h}$, relative to controls. At $6 \mathrm{~h}$ post-treatment, the APAP-treated mice showed elevation of 2-aminoadipate, glutamate, D-3-HB and valine, while AMP and glucose were depleted relative to
Statistical significance is shown by the asterisks, * and ** $(p<0.05$ and $p<0.01$, respectively)

controls. In contrast to APAP, AMAP administration did not lead to any statistically significant metabolic differences in the ${ }^{1} \mathrm{H}-\mathrm{NMR}$ metabolic profiles, relative to controls, throughout the time course of the study. The integrals and summary of the statistically significant differences identified by ${ }^{1}$ H-NMR spectroscopy are presented in Fig. 3a and Table 1, respectively. Table 4 in the Suppl. material displays the 
Table 2 Summary of discriminatory metabolites identified by GC-MS analysis of the hepatic extracts after APAP/AMAP administration

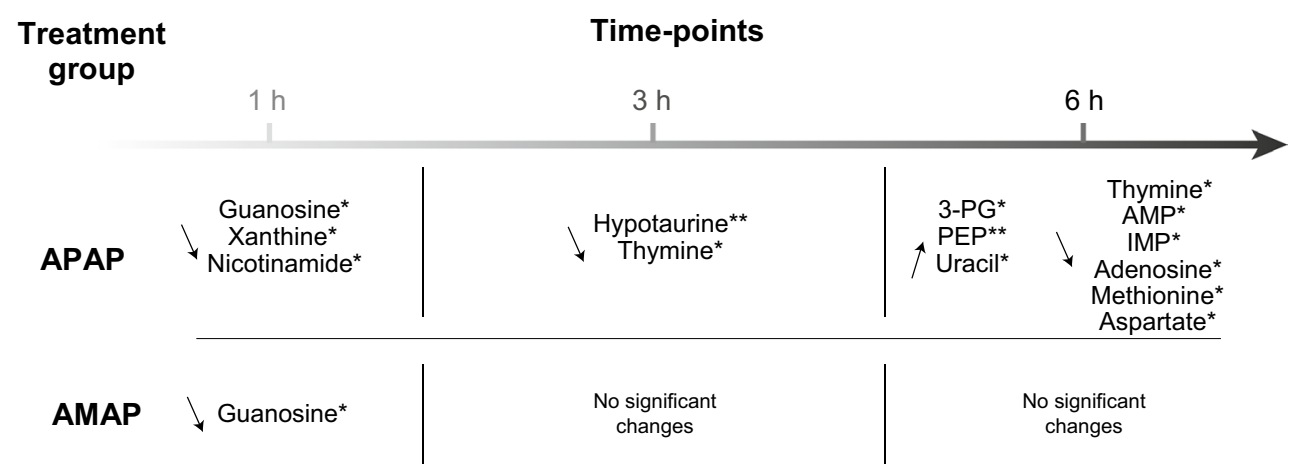

ANOVA coupled to Bonferroni multiple test correction was used. Statistical significance is shown by the asterisks, $*$ and $* *(p<0.05$ and $p<0.01$, respectively). Key: IMP-inosine monophosphate; AMP-adenosine monophosphate; PEP-phosphoenolpyruvate; 3-PG-3-phosphoglycerate

individual ${ }^{1} \mathrm{H}-\mathrm{NMR}$ resonance integral values for all metabolites analyzed.

\section{GC-MS-detected endogenous changes in hepatic extracts after AMAP and APAP administration}

The GC-MS analysis of the hepatic extracts indicated that APAP treatment resulted in elevated quantities of xanthine, guanosine and nicotinamide at $1 \mathrm{~h}$, together with reduced levels of hypotaurine, tryptophan and thymine at $3 \mathrm{~h}$, relative to the controls. At $6 \mathrm{~h}$ post-treatment, lower amounts of hypotaurine, adenosine, methionine, AMP, aspartate and tyrosine were observed, while hepatic concentrations of phosphoenolpyruvate, 3-phosphoglycerate and uracil had increased relative to the control mice. The parallel analysis of the AMAP-treated groups revealed elevation of guanosine at $1 \mathrm{~h}$ relative to control mice. There were no statistically significant metabolic perturbations at either the 3-or 6-h time-points following AMAP treatment. The integrals and summary of the GC-MS-detected statistically significant hepatic metabolic perturbations induced by both AMAP and APAP are presented in Fig. 4 and summarized in Table 2, respectively. Table 5 in the Suppl. material displays the individual GC-MS integral values for all metabolites analyzed.

\section{Discussion}

The simultaneous characterization of xenobiotic metabolism and endogenous metabolic perturbations induced by AMAP and APAP treatment was achieved using a combination of ${ }^{1} \mathrm{H}-\mathrm{NMR}$ and GC-MS analysis. This comparative metabonomic approach provided complementary mechanistic insight into the adaptation of hepatic metabolism to toxic insult and enabled the identification of unique metabolic phenotypes for each treatment. Following APAP administration, glutathione conjugates were detected at $1 \mathrm{~h}$ post-treatment in the hepatic extracts (APAP glutathionyl, APAP- $N$-acetylcysteinyl) and urinary metabolic profiles (APAP cysteinyl and APAP- $N$-acetylcysteinyl), reflecting both the production and detoxification of the electrophilic reactive metabolite of APAP, NAPQI. This corroborated the marked depletion of hepatic glutathione (sum of reduced and oxidized forms) at $1 \mathrm{~h}$ and $3 \mathrm{~h}$ post-treatment. This depletion will have likely led to further downstream metabolic effects, such as the GC-MS-detected depletion of hepatic hypotaurine at $3 \mathrm{~h}$ and $6 \mathrm{~h}$ and methionine at $6 \mathrm{~h}$ post-treatment, which are precursors of glutathione. This may reflect the cellular response to APAP-induced oxidative stress which has been previously reported to lead to the depletion of sulfur-containing metabolites such as hypotaurine (Soga et al. 2006; Yamazaki et al. 2013) and methionine (Yamazaki et al. 2013) (Fig. 5).

The observed hepatic elevation of the mitochondrial metabolite succinate, at $3 \mathrm{~h}$ post-treatment, as well as glutamate at $3 \mathrm{~h}$ and $6 \mathrm{~h}$ post-treatment, suggested APAPinduced mitochondrial dysfunction as a key event in the onset of hepatotoxicity. These perturbations which preceded the histopathological observation of necrosis may reflect mitochondrial disruption as a result of the inability of mitochondria to utilize tricarboxylic acid cycle intermediates (Burcham and Harman 1991). APAP administration has been previously demonstrated to up-regulate succinate dehydrogenase (a component of the electron transport chain) in C57BL/6 mice, which would affect succinate levels (Stamper et al. 2011). Finally, disruption of the tricarboxylic acid cycle and the previously reported APAP-induced disruption of glutamate dehydrogenase (Halmes et al. 1996) could also be responsible for the observed elevation of hepatic glutamate.

Impaired mitochondrial respiration and ATP synthesis in response to APAP exposure would lead to the up-regulation of other energy-related pathways (Katyare and Satav 


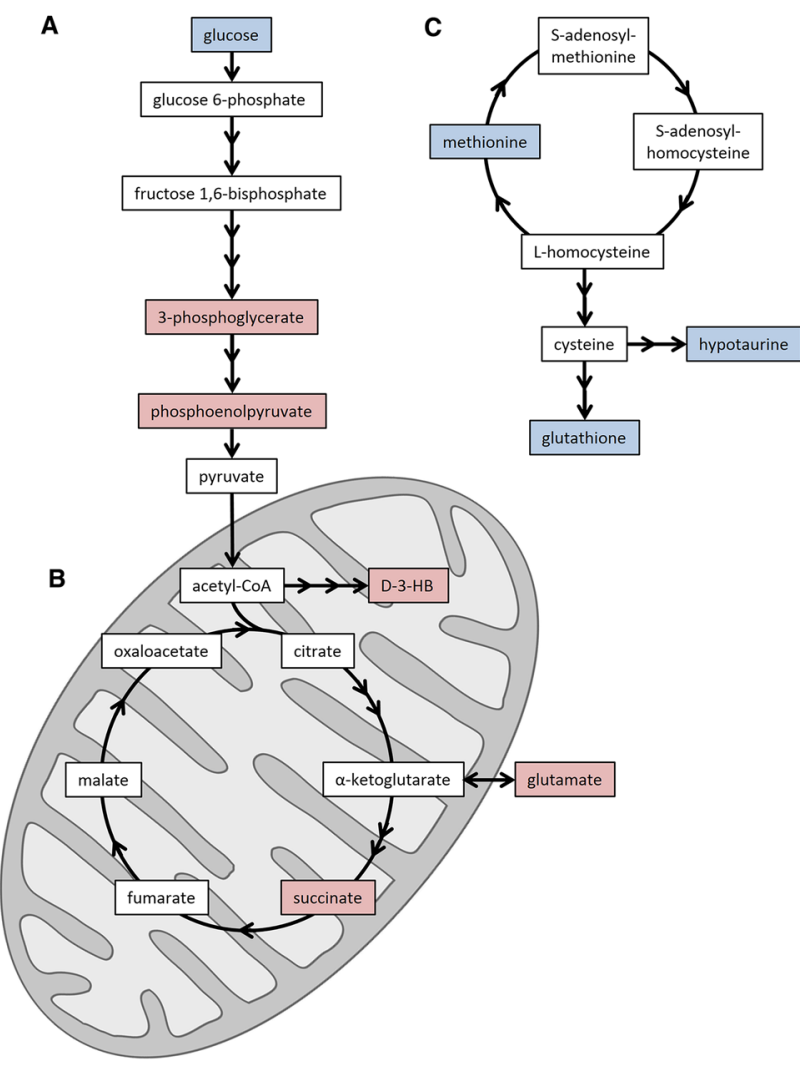

Fig. 5 Summary of hepatic metabolic perturbations associated with APAP-induced mitochondrial dysfunction and oxidative stress. Diagrammatic representations of the glycolysis pathway (a) and tricarboxylic acid cycle (b), as well as the methionine-homocysteine cycle and glutathione synthesis (c) are shown. Red shading depicts an APAP-induced elevation, while blue shading represents an APAPinduced depletion. Key D-3-HB, D-3-hydroxybutyrate (color figure online)

1989). The depletion of glycogen and glucose coupled with the elevation of D-3-HB seen in the hepatic ${ }^{1} \mathrm{H}-\mathrm{NMR}$ metabolic profiles at $6 \mathrm{~h}$ post-treatment provides evidence of the energetic stress exerted by APAP (Coen et al. 2003). This finding suggests a possible shift from mitochondrial oxidative phosphorylation to glycolysis and supports earlier metabonomic-based study findings (Coen et al. 2003, 2004). This shift could also explain the higher levels of hepatic phosphoenolpyruvate and 3-phosphoglycerate that were detected by GC-MS analysis at the same time-point (Fig. 5).

Finally, APAP was also observed to induce a decrease in the hepatic concentration of guanosine at $1 \mathrm{~h}$ (GC-MS analysis) and AMP ( ${ }^{1} \mathrm{H}-\mathrm{NMR}$ and GC-MS analyses) and adenosine (GC-MS analysis) at $6 \mathrm{~h}$ post-treatment. APAP has previously been reported to affect nucleoside and nucleotide metabolism through the inhibition of enzymes such as adenosine deaminase (Ataie et al. 2004); however, the exact mechanism is uncertain. It is possible that the observed hepatic effect could be linked to the depletion of ATP levels and the subsequent utilization of adenine nucleotides in the liver in an attempt to compensate for energy loss (Tirmenstein and Nelson 1990). The panel of APAP-induced discriminatory metabolites and associated metabolic pathways identified in this work is summarized in Fig. 5.

In contrast to APAP, the histopathological analysis suggested that AMAP administration $(300 \mathrm{mg} / \mathrm{kg})$ did not lead to hepatotoxicity in the form of centrilobular necrosis within the 6-h timescale studied. The absence of AMAP glutathionyl conjugates in the hepatic and urinary profiles and the absence of perturbation of endogenous hepatic glutathione contrasted with APAP and suggested the absence of AMAP-induced oxidative stress, which could explain the difference in toxicity between the two compounds (Hamilton and Kissinger 1986). This finding is in agreement with previous findings which showed the urinary excretion of the cysteinyl and mercapturic acid conjugates of AMAP represented $5 \%$ of the dose (600 mg/kg, male Swiss Webster mice). In contrast, urinary excretion of the cysteinyl and mercapturic acid conjugates of APAP represented ca. $20 \%$ of the dose $(250 \mathrm{mg} / \mathrm{kg})$ (Rashed et al. 1990). Assuming that administration of these isomers at the same doses results in equivalent hepatic exposures, such a result could simply reflect differences in their propensities for bioactivation, or alternatively their relative affinities for alternative routes of metabolism, such as glucuronidation, that result in detoxification.

Following treatment with AMAP, discriminatory metabolites were identified at the earliest $1 \mathrm{~h}$ post-treatment timepoint with metabolic homeostasis restored at $3 \mathrm{~h}$ and $6 \mathrm{~h}$ post-treatment, when ${ }^{1} \mathrm{H}-\mathrm{NMR}$ spectroscopic profiles of AMAP-treated animals were indistinguishable from controls. The histopathology analysis revealed that two animals developed hepatic grade 1 and 2 centrilobular eosinophilia at the 6-h time-point. The presence of centrilobular eosinophilia suggests that AMAP administration may have led to centrilobular necrosis at a later time-point in these two animals. However, within our 6-h equimolar dose comparative study, AMAP was not found to have in common any metabolic perturbations identified in the APAP-treated mice, which included markers for the development of oxidative stress and mitochondrial dysfunction.

In summary, we applied a comparative metabonomic approach to generate metabolic phenotypes of AMAP and APAP exposure, which was anchored with traditional histopathological assessment. APAP administration caused oxidative stress at an early time-point and subsequently induced energetic stress as evidenced from the impairment 
of mitochondrial function and up-regulation of glycolysis. AMAP was observed to have an early, transient, metabolic effect that was reversible by $6 \mathrm{~h}$ and did not lead to a hepatotoxic endpoint.

Acknowledgments This work was supported by the MRC Integrative Toxicology Training Partnership (ITTP), which is gratefully acknowledged for providing financial support to M.K. and L.M. in the form of a studentship grant and to M.C. in the form of a career development fellowship. We would also like to thank Hector Keun, Volker Behrends and Gregory Tredwell for assisting with the GC-MS analysis and providing access to instrumentation.

\section{Compliance with ethical standards}

Conflict of interest The authors declare that there is no conflict of interest.

Open Access This article is distributed under the terms of the Creative Commons Attribution 4.0 International License (http://creativecommons.org/licenses/by/4.0/), which permits unrestricted use, distribution, and reproduction in any medium, provided you give appropriate credit to the original author(s) and the source, provide a link to the Creative Commons license, and indicate if changes were made.

\section{References}

Ataie G et al (2004) Kinetic and structural analysis of the inhibition of adenosine deaminase by acetaminophen. J Enzyme Inhib Med Chem 19:71-78. doi:10.1080/14756360310001632741

Bajt ML, Cover C, Lemasters JJ, Jaeschke H (2006) Nuclear translocation of endonuclease $\mathrm{G}$ and apoptosis-inducing factor during acetaminophen-induced liver cell injury. Toxicol Sci 94:217225. doi:10.1093/toxsci/kfl077

Bales JR, Sadler PJ, Nicholson JK, Timbrell JA (1984) Urinary excretion of acetaminophen and its metabolites as studied by proton NMR spectroscopy. Clin Chem 30:1631-1636

Beckonert O, Keun HC, Ebbels TM, Bundy J, Holmes E, Lindon JC, Nicholson JK (2007) Metabolic profiling, metabolomic and metabonomic procedures for NMR spectroscopy of urine, plasma, serum and tissue extracts. Nat Protoc 2:2692-2703. doi:10.1038/nprot.2007.376

Behrends V, Tredwell GD, Bundy JG (2011) A software complement to AMDIS for processing GC-MS metabolomic data. Anal Biochem 415:206-208. doi:10.1016/j.ab.2011.04.009

Bessems JG, Vermeulen NP (2001) Paracetamol (acetaminophen)induced toxicity: molecular and biochemical mechanisms, analogues and protective approaches. Crit Rev Toxicol 31:55-138. doi:10.1080/20014091111677

Beyer RP et al (2007) Multicenter study of acetaminophen hepatotoxicity reveals the importance of biological endpoints in genomic analyses. Toxicol Sci 99:326-337. doi:10.1093/toxsci/kfm150

Bhattacharyya $S$ et al (2014) Targeted liquid chromatography-mass spectrometry analysis of serum acylcarnitines in acetaminophen toxicity in children. Biomark Med 8:147-159. doi:10.2217/ bmm. 13.150

Burcham PC, Harman AW (1991) Acetaminophen toxicity results in site-specific mitochondrial damage in isolated mouse hepatocytes. J Biol Chem 266:5049-5054

Chen C, Krausz KW, Shah YM, Idle JR, Gonzalez FJ (2009) Serum metabolomics reveals irreversible inhibition of fatty acid beta-oxidation through the suppression of PPARalpha activation as a contributing mechanism of acetaminophen-induced hepatotoxicity. Chem Res Toxicol 22:699-707. doi:10.1021/tx800464q

Cloarec O et al (2005) Statistical total correlation spectroscopy: an exploratory approach for latent biomarker identification from metabolic 1H NMR data sets. Anal Chem 77:1282-1289. doi:10.1021/ac048630x

Coen M (2014) Metabolic phenotyping applied to pre-clinical and clinical studies of acetaminophen metabolism and hepatotoxicity. Drug Metab Rev. doi:10.3109/03602532.2014.982865

Coen M, Lenz EM, Nicholson JK, Wilson ID, Pognan F, Lindon JC (2003) An integrated metabonomic investigation of acetaminophen toxicity in the mouse using NMR spectroscopy. Chem Res Toxicol 16:295-303. doi:10.1021/tx0256127

Coen M, Ruepp SU, Lindon JC, Nicholson JK, Pognan F, Lenz EM, Wilson ID (2004) Integrated application of transcriptomics and metabonomics yields new insight into the toxicity due to paracetamol in the mouse. J Pharm Biomed Anal 35:93-105. doi:10.1016/j.jpba.2003.12.019

Coen M, Holmes E, Lindon JC, Nicholson JK (2008) NMR-based metabolic profiling and metabonomic approaches to problems in molecular toxicology. Chem Res Toxicol 21:9-27. doi:10.1021/ tx700335d

Dahlin DC, Nelson SD (1982) Synthesis, decomposition kinetics, and preliminary toxicological studies of pure $N$-acetyl- $p$-benzoquinone imine, a proposed toxic metabolite of acetaminophen. $\mathbf{J}$ Med Chem 25:885-886

Dieterle F, Ross A, Schlotterbeck G, Senn H (2006) Probabilistic quotient normalization as robust method to account for dilution of complex biological mixtures. Application in 1H NMR metabonomics. Anal Chem 78:4281-4290. doi:10.1021/ac051632c

Dunn WB et al (2011) Procedures for large-scale metabolic profiling of serum and plasma using gas chromatography and liquid chromatography coupled to mass spectrometry. Nat Protoc 6:1060 1083. doi:10.1038/nprot.2011.335

Fiehn O (2008) Extending the breadth of metabolite profiling by gas chromatography coupled to mass spectrometry. Trends Anal Chem 27:261-269. doi:10.1016/j.trac.2008.01.007

Fountoulakis M, Berndt P, Boelsterli UA, Crameri F, Winter M, Albertini S, Suter L (2000) Two-dimensional database of mouse liver proteins: changes in hepatic protein levels following treatment with acetaminophen or its nontoxic regioisomer 3-acetamidophenol. Electrophoresis 21:2148-2161. doi: 10.1002/1522-2683(20000601)21:11<2148:AIDELPS2148>3.0.CO;2-X

Ghauri FY, McLean AE, Beales D, Wilson ID, Nicholson JK (1993) Induction of 5-oxoprolinuria in the rat following chronic feeding with N-acetyl 4-aminophenol (paracetamol). Biochem Pharmacol 46(5):953-957

Hadi M et al (2013) AMAP, the alleged non-toxic isomer of acetaminophen, is toxic in rat and human liver. Arch Toxicol 87:155165. doi:10.1007/s00204-012-0924-1

Halmes NC, Hinson JA, Martin BM, Pumford NR (1996) Glutamate dehydrogenase covalently binds to a reactive metabolite of acetaminophen. Chem Res Toxicol 9:541-546. doi:10.1021/ tx950158a

Hamilton M, Kissinger PT (1986) The metabolism of 2- and 3-hydroxyacetanilide. Determination of metabolic products by liquid chromatography/electrochemistry. Drug Metab Dispos 14:5-12

Howell BA, Siler SQ, Watkins PB (2014) Use of a systems model of drug-induced liver injury (DILIsym((R))) to elucidate the mechanistic differences between acetaminophen and its less-toxic isomer. AMAP Mice Toxicol Lett 226:163-172. doi:10.1016/j. toxlet.2014.02.007 
Jaeschke H, McGill MR, Ramachandran A (2012) Oxidant stress, mitochondria, and cell death mechanisms in drug-induced liver injury: lessons learned from acetaminophen hepatotoxicity. Drug Metab Rev 44:88-106. doi:10.3109/03602532.2011.6026 88

Katyare SS, Satav JG (1989) Impaired mitochondrial oxidative energy metabolism following paracetamol-induced hepatotoxicity in the rat. Br J Pharmacol 96:51-58

Kind T, Wohlgemuth G, do Lee Y, Lu Y, Palazoglu M, Shahbaz S, Fiehn O (2009) FiehnLib: mass spectral and retention index libraries for metabolomics based on quadrupole and time-offlight gas chromatography/mass spectrometry. Anal Chem 81:10038-10048. doi:10.1021/ac9019522

Landin JS, Cohen SD, Khairallah EA (1996) Identification of a 54-kDa mitochondrial acetaminophen-binding protein as aldehyde dehydrogenase. Toxicol Appl Pharmacol 141:299-307. doi:10.1006/taap.1996.0287

Lee WM (2012) Recent developments in acute liver failure. Best Pract Res Clin Gastroenterol 26:3-16. doi:10.1016/j.bpg.2012.01.014

Lindon JC, Keun HC, Ebbels TM, Pearce JM, Holmes E, Nicholson JK (2005) The Consortium for Metabonomic Toxicology (COMET): aims, activities and achievements. Pharmacogenomics 6:691-699. doi:10.2217/14622416.6.7.691

Masubuchi Y, Suda C, Horie T (2005) Involvement of mitochondrial permeability transition in acetaminophen-induced liver injury in mice. J Hepatol 42:110-116. doi:10.1016/j.jhep.2004.09.015

McGill MR, Sharpe MR, Williams CD, Taha M, Curry SC, Jaeschke $\mathrm{H}$ (2012a) The mechanism underlying acetaminophen-induced hepatotoxicity in humans and mice involves mitochondrial damage and nuclear DNA fragmentation. J Clin Invest 122:15741583. doi:10.1172/JCI59755

McGill MR, Williams CD, Xie Y, Ramachandran A, Jaeschke H (2012b) Acetaminophen-induced liver injury in rats and mice: comparison of protein adducts, mitochondrial dysfunction, and oxidative stress in the mechanism of toxicity. Toxicol Appl Pharmacol 264:387-394. doi:10.1016/j.taap.2012.08.015

Miner DJ, Kissinger PT (1979) Evidence for the involvement of $\mathrm{N}$-acetyl-p-quinoneimine in acetaminophen metabolism. Biochem Pharmacol 28:3285-3290

Nelson EB (1980) The pharmacology and toxicology of meta-substituted acetanilide I: acute toxicity of 3-hydroxyacetanilide in mice. Res Commun Chem Pathol Pharmacol 28:447-456

Nicholls AW, Caddick S, Wilson ID, Farrant RD, Lindon JC, Nicholson JK (1995) High resolution NMR spectroscopic studies on the metabolism and futile deacetylation of 4-hydroxyacetanilide (paracetamol) in the rat. Biochem Pharmacol 49:1155-1164

Nicholls AW, Wilson ID, Godejohann M, Nicholson JK, Shockcor JP (2006) Identification of phenacetin metabolites in human urine after administration of phenacetin- $\mathrm{C} 2 \mathrm{H} 3$ : measurement of futile metabolic deacetylation via HPLC/MSSPE-NMR and HPLC-ToF MS. Xenobiotica 36:615-629. doi:10.1080/00498250600711113

Nicholson JK, Foxall PJ, Spraul M, Farrant RD, Lindon JC (1995) $750 \mathrm{MHz} 1 \mathrm{H}$ and $1 \mathrm{H}-13 \mathrm{C}$ NMR spectroscopy of human blood plasma. Anal Chem 67:793-811

Nicholson JK, Lindon JC, Holmes E (1999) 'Metabonomics': understanding the metabolic responses of living systems to pathophysiological stimuli via multivariate statistical analysis of biological NMR spectroscopic data. Xenobiotica 29:1181-1189. doi:10.1080/004982599238047

Pierce RH et al (2002) Cell culture model for acetaminophen-induced hepatocyte death in vivo. Biochem Pharmacol 64:413-424
Placke ME, Ginsberg GL, Wyand DS, Cohen SD (1987) Ultrastructural changes during acute acetaminophen-induced hepatotoxicity in the mouse: a time and dose study. Toxicol Pathol $15: 431-438$

Priyadarsiny P et al (2008) Differential gene expression analysis of a known hepatotoxin, $N$-acetyl- $p$-amino-phenol (APAP) as compared to its non-toxic analog, $N$-acetyl- $m$-amino-phenol (AMAP) in mouse liver. J Toxicol Sci 33:163-173

Rashed MS, Myers TG, Nelson SD (1990) Hepatic protein arylation, glutathione depletion, and metabolite profiles of acetaminophen and a non-hepatotoxic regioisomer, $3^{\prime}$-hydroxyacetanilide, in the mouse. Drug Metab Dispos 18:765-770

Roberts SA, Jollow DJ (1978) Acetaminophen structure-toxicity relationships: why is 3 -Hydroxyacetanilide not hepatotoxic. Pharmacologist 20:259

Russmann S, Kullak-Ublick GA, Grattagliano I (2009) Current concepts of mechanisms in drug-induced hepatotoxicity. Curr Med Chem 16:3041-3053

Sangster T, Major H, Plumb R, Wilson AJ, Wilson ID (2006) A pragmatic and readily implemented quality control strategy for HPLC-MS and GC-MS-based metabonomic analysis. Analyst 131(10):1075-1078

Soga $\mathrm{T}$ et al (2006) Differential metabolomics reveals ophthalmic acid as an oxidative stress biomarker indicating hepatic glutathione consumption. J Biol Chem 281:16768-16776. doi:10.1074/jbc. M601876200

Spurway TD, Gartland KP, Warrander A, Pickford R, Nicholson JK, Wilson ID (1990) Proton nuclear magnetic resonance of urine and bile from paracetamol dosed rats. J Pharm Biomed Anal 8:969-973

Stamper BD, Bammler TK, Beyer RP, Farin FM, Nelson SD (2010) Differential regulation of mitogen-activated protein kinase pathways by acetaminophen and its nonhepatotoxic regioisomer 3'-hydroxyacetanilide in TAMH cells. Toxicol Sci 116:164-173. doi:10.1093/toxsci/kfq100

Stamper BD, Mohar I, Kavanagh TJ, Nelson SD (2011) Proteomic analysis of acetaminophen-induced changes in mitochondrial protein expression using spectral counting. Chem Res Toxicol 24:549-558. doi:10.1021/tx1004198

Streeter AJ, Bjorge SM, Axworthy DB, Nelson SD, Baillie TA (1984) The microsomal metabolism and site of covalent binding to protein of 3'-hydroxyacetanilide, a nonhepatotoxic positional isomer of acetaminophen. Drug Metab Dispos 12:565-576

Tirmenstein MA, Nelson SD (1989) Subcellular binding and effects on calcium homeostasis produced by acetaminophen and a nonhepatotoxic regioisomer, 3 '-hydroxyacetanilide, in mouse liver. J Biol Chem 264:9814-9819

Tirmenstein MA, Nelson SD (1990) Acetaminophen-induced oxidation of protein thiols. Contribution of impaired thiol-metabolizing enzymes and the breakdown of adenine nucleotides. J Biol Chem 265:3059-3065

Ward JM, Thoolen B (2011) Grading of lesions. Toxicol Pathol 39:745-746. doi:10.1177/0192623311408622

Xie Y et al (2015) Mitochondrial protein adducts formation and mitochondrial dysfunction during $N$-acetyl- $m$-aminophenol (AMAP)induced hepatotoxicity in primary human hepatocytes. Toxicol Appl Pharmacol. doi:10.1016/j.taap.2015.09.022

Yamazaki M et al (2013) Perturbation of bile acid homeostasis is an early pathogenesis event of drug induced liver injury in rats. Toxicol Appl Pharmacol 268:79-89. doi:10.1016/j.taap.2013.01.018 